\title{
Failures in incentive transmission along Brazil's quality beef chain ${ }^{1}$
}

\author{
Silvia Morales de Queiroz Caleman ${ }^{1}$ and Decio Zylbersztajn ${ }^{2}$ \\ ${ }^{1}$ Federal University of Mato Grosso do Sul, Department of Economics and Administration, Cidade Universitária, Caixa Postal 549, \\ CEP 79070-900 Campo Grande, MS,Brazil; silviacaleman@gmail.com \\ ${ }^{2}$ University of São Paulo, School of Economics, Business and Accounting, Knowledge Center in Agro-Industrial Studies - PENSA, Av. \\ Prof. Luciano Gualberto 908, sala C14, São Paulo Brazil; dezylber@usp.br
}

\begin{abstract}
Coordination mechanisms are key factors that affect the competitiveness of agrisystems. Brazilian beef chains are associated with less formal contractual relations compared to other food chains, resulting in frequent conflicts between cattle farmers and the processing industry. This study identifies the reasons for this phenomenon, raising the question of whether the observed incentive structures actually promote cooperation between production and industry. The study aims to explore the role of institutions and incentive structures in coordination failures within beef quality programs coordinated by the meatpacking industry. The issue is treated by considering the principal-agent theory and Transaction Costs Economics. We propose a model of incentive structures for the production of quality beef which considers specific investments made by cattle raisers and the meatpacking industry. In addition to specific investments, we also consider the role institutions play in reducing organizational failures. We adopt a mathematical and a strategic model to which game theory is applied. Quality is addressed using a multidimensional approach, since different product attributes are considered. The theoretical model is then validated in a multiple case study with three quality beef programs. The findings suggest that the complexity of designing efficient incentive structures makes the maintenance of beef quality programs an arduous task. The institutional role represented by formal contracts and horizontal coordination is a relevant aspect that has yet to be considered in preventing organizational failures. This study has academic and managerial implications.
\end{abstract}

Keywords: bovine meat, institutions, contracts, coordination

\section{Introduction}

Coordination mechanisms are key factors that determine agrisystems' competitiveness (Zylbersztajn, 1996). Coordination implies, among other things, the offer of incentives for cooperation in order to increase value, the design of mechanisms which allow the components to share the value created, and finally the conciliation of divergent interests. Transaction Cost Economics (TCE) and incentive theory (IT) delimit the problem, respectively, under the lenses of asset specificity and transaction cost economizing perspectives, and incentive structures motivated by the search for efficiency. Among different forms of coordination mechanisms, contracts emerge as a possible choice.

In agrisystem coordination literature, contracts assume an important role (Martinez and Zering, 2004; Menard, 1996; Menard and Klein, 2004; Zylbersztajn, 2005; Zylbersztajn and Farina, 2010). Different contract structures are observed in different production activities. In the United States, $47 \%$ of animal production occurs based on some form of contract, and the production of beef presents the lower

\footnotetext{
${ }^{1}$ This paper is part of a research project that received a grant from the National Council of Scientific Research- CNPq.
}

indices of contract adoption (MacDonald and Korb, 2006). In Brazil, contracts cover a growing share of agricultural activities (Zylbersztajn, 2005). However, when it comes to the animal sector, just as in the USA, beef production is less aligned with contractual governance modes. Why is this so? Are the market and vertically integrated structures enough to promote cooperation between production and industry? What role do institutions play? This paper aims to identify the reasons for the low rate of adoption of formal contracts by examining contractual arrangements in top-quality beef production strategies developed by some Brazilian meat companies.

The Brazilian beef chain is characterized by complexity and diversity. The demand for traceable quality products is motivated by health, social, and environmental concerns. Specific quality requirements demand close coordination between industry and production, and thereby pose new challenges for this sector. The processing industries, mainly those oriented to quality-sensitive markets, have developed quality programs based on carcass classification and standardization. These programs aim to create an incentive for the production of standardized cattle, which is a source of industrial process optimization and quality production. Compensation is given to cattle growers as a 
form of incentive to stimulate the production of particular quality attributes.

Some obstacles to adopting incentive mechanisms to induce cooperation are found in the Brazilian beef chain. Typical problems are related to matching cooperating costs to value creation, and finding institutional structures of production that promote the equitable sharing of benefits. Both agents, i.e. cattle farmers and industry, discredit the effectiveness of so-called quality programs, although they affirm that cooperation is the way to create value. This paradox points to the relevance of analyzing coordination imperfections. Traditionally, the literature focuses on efficiency models, neglecting the perspective of organizational failures. This is the main contribution of this paper.

This study thus focuses on the pattern of contracts in Brazilian quality beef programs, considering the imperfections in institutional arrangement mechanisms. Three research questions are addressed: (1) what are the regularities associated with the failures of the incentive structure to promote cooperation; (2) what are the risks perceived by the players; and (3) what role can institutions play in fixing the problem?

\section{Theoretical framework}

The subject of vertical coordination is treated considering two theoretical frameworks: (1) principal agent theory; and (2) transaction costs economics (TCE), both of which consider the concept of incentives. The first treats incentives based on ex ante contracts, where risk and benefits are defined in order to provide the necessary incentives for the transaction. Due to contract incompleteness and bounded rationality, TCE considers ex post negotiation, since agents are not fully rational. The investment in specific assets creates the possibility of quasi-rent capture in the presence of opportunism. For this approach, observed institutional arrangements provide the necessary incentives for the economic transaction.

\section{Principal-agent theory}

The principal-agent problem arises when one party (the principal) delegates to another (the agent) a task. In conditions of informational asymmetry and measurement costs, the principal might not have access to all information gathered by the agent, resulting in imperfect performance assessment. In the presence of rationality and self-interested behavior, both principal and agent seek to maximize their utility, but since their goals may be conflicting, a situation of agency cost is present. Contracts are designed ex-ante to create incentives and provide mechanisms for monitoring performance as a way to control for agency costs.

As stated by Jensen and Meckling (1976), the agency cost is the sum of: (1) monitoring costs; (2) bonding costs premiums paid to the agent as an incentive; and (3) the residual loss. The authors emphasize that agency costs also apply to cooperative relationships, provided that a principalagent relationship is established.

The existence of informational asymmetry is associated with two main elements: hidden information and hidden action. The idea of hidden information is related to the concept of adverse selection as presented by Akerlof (1970). In the presence of informational asymmetry, the seller knows the product quality better than the buyer. The process of adverse selection leads the buyer to consider and pay only for the average quality of the product. Thus, the lemons problem arises.

The assumption of hidden action, also called moral hazard, is presented by Eisenhardt (1989) as the lack of the agent's effort to apply himself to the execution of the task in accordance with the principal's interest. Due to the hidden action problem, the difficulty in observing and/or measuring the agent's action, or even the monitoring cost, there is room for cheating. Eisenardt highlights that risk is a relevant aspect to be considered in a principal-agent relationship, especially when the agent has different preferences in the face of risk. The evaluation of the agent's profile - whether riskseeking, risk neutral, or risk averse - is crucial for cooperative relationships, particularly when the parties have conflicting goals. The identification of the incentives to align the agent's performance with the principal's interest is important in order to build a cooperative relationship. The problem then becomes designing a contract that adequately addresses the variables involved in this equation: fixed wages, premium prices, cost, and risk.

The classical principal-agent model looks for the optimal allocation of risk and premiums (incentives) of production, considering a system of efficient compensation. Holmstrom and Milgrom (1991) affirm that this model generates limited results, as it does not allow the delineation of more complex organizational problems, for instance tasks with different dimensions or multitasks. This concept is related to the different tasks that the agent must execute to reach the desired result as established by the principal. According to these authors, when the agent has multiple tasks to execute, the incentive not only serves to place the risk and to motivate the effort, but also to direct the action of the agent to one determined dimension of the task. In other words, depending on the incentive, the marginal benefit of one activity increases at the expense of another. Thus, the expected results could be perverse, depending on how 
the general incentive is proposed. In synthesis, the agent, when allocating efforts among different tasks, tends to make a greater effort in that dimension which generates greater rewards. The multitask model applies to situations which involve different tasks for the same agents, and also tasks with different dimensions.

Gibbons (1998) highlights a limitation of the classical principal-agent model, concerning the assumption that the result is assumed to be measurable and that performance is only estimated. Relational contracts emerge when reputational factors are present and subjective incentive measures are present in the model.

\section{Transaction cost economics}

Taking an alternative perspective, TCE analyzes the contractual world by considering assumptions about bounded rationality and opportunism. The structure that minimizes transaction costs must also consider the transaction's attributes: frequency, asset specificity, and uncertainty. Williamson (1985) argues that asset specificity is the key variable for identifying the most efficient form of governance. An asset is considered specific to a transaction when alternative allocations imply loss of value. The more specific the involved assets are, the higher the possibility of contractual breaches will be, since the specificity can almost result in the existence of rents that can be captured in the transaction (Klein et al., 1978; Williamson, 1985). Williamson (1996) points out that the governance mechanism must be understood as an incentive structure, which was defined by Ronald Coase as the institutional structure of production. Furthermore, it plays the role of mitigating conflicts and guaranteeing mutual benefits. For TCE, ex-ante incentives are not enough for the promotion of cooperation, in contrast to what the principal-agent theory proposes. Moreover, the governance mechanism also has to consider the necessity of ex-post adaptations, and the fact that incentives are not essentially pecuniary. The governance structure itself is an incentive for the emergence of a cooperative environment.

The behavioral assumptions in TCE are bounded rationality and opportunism. The idea of bounded rationality departs from Simon's concept (1991) that agents are intentionally rational but they are so in a limited way, and the opportunistic behavior implies the possibility of an expost contract breach, opening space for moral hazard and hold-up events: hence the necessity of creating contract safeguards ex-ante.

According to Williamson (1996), the existence of incomplete contracts accounts for a significant number of economic problems. Based on the assumptions of bounded rationality and opportunistic behavior, the presence of contractual safeguards becomes an important factor in understanding how to proceed from a long-term perspective. Zylbersztajn and Zuurbier (2009) argue that the challenge is to design complete and comprehensive contracts to cover the contingencies which arise from opportunistic behavior and business environment uncertainties. Moreover, to consider spontaneous cooperation as a solution for contract failures would be only possible in absence of opportunism, which is not aligned with the basic assumptions of TCE.

\section{General hypotheses}

In this research, coordination failures in strictly coordinated beef quality subsystems are investigated based on the following hypotheses:

Hypothesis 1: The failure in coordinating quality beef subsystems is related to failures in the transmission of monetary incentives along the chain.

Hypothesis 2: Formal and informal institutions affect the existence, persistence, and intensity of the observed organizational failures.

\section{Methodological approach}

Mathematical and strategic models were developed and applied to a multi-case study. The first provides a simplified analysis of the relationship between the producer and company for the transaction of quality products. The second, through the application of game theory, identifies the agents' behavior in the face of informational asymmetry. Both models were developed considering two modes of coordination: (1) subsystem 1: vertical coordination between beef farmers and processing companies active in the production of young steers; and (2) subsystem 2: horizontal and vertical coordination in which beef farmers are organized horizontally in the first step in order to transact a credence good - organic beef - with a meat packer. The theoretical models are based on the study of dynamic governance within complex agrisystem networks proposed by Zylbersztajn and Farina (2010).

The qualitative approach was developed with three beef exporting companies with relevant market share in the Brazilian beef export market. The data was collected through semi-structured interviews conducted with the managers of these companies' quality programs. Two cases investigate the companies herein called Alpha and Beta, characterizing subsystem 1. The company herein called Sigma is an example of subsystem 2. Considering investments in specific assets made by beef farmers and industry, the proposed 
theoretical model attempts to delineate the necessary incentive structure for producing quality beef. For this purpose, the multidimensional character of quality is considered, based on the concept of a bundle of attributes being transacted.

\section{Theoretical model}

The developed model pictures the interaction between the supplier (beef farmer) and the purchaser (processing industry). The economic analysis is based on a rational choice model, considering that first, individuals are autonomous, rational and self-interested; second, an individual maximizes his or her utility; and third, information is asymmetric, opening room for moral hazard and adverse selection.

The models illustrate the exchange between beef farmers and the beef industry, focusing on quality products. Quality is understood to be composed of a bundle of desirable attributes defined by the industry. The objective is to build an incentive structure in order to induce the supplier to care about the specifications established by the industry. Cattle raisers agree to undertake specific investments related to quality production, since premium prices are paid to compensate for the added costs and the risk involved with the possibility of quasi-rent capture. The industry also makes specific investments. In the presence of specific assets, quasirents are created, opening room for capture of value. Failures are observed in this type of institutional arrangement.

Subsequently, a model of strategic behavior was developed, adding a dynamic component to the transaction - two cases were modeled, one with the presence of a formal contract and the other including the payment of a bonus for quality by the company.

The model requires the interaction of two agents, the beef farmer (P) and the processing company (I). The meat presents a variable level of quality, where (M) represents the bundle of attributes defined by the industry.

Farmers are willing to make specific investments $\left(e_{p}\right)$ in quality production, since the incentives generated by the company compensate them for the incurring of costs $\left(c_{e p}\right)$ and risk $(\mathrm{w})$ which arise from the production of quality attributes. In the presence of specific investments, quasirents are created, opening room for capture. The processing company also makes specific investments (i) for the processing of superior quality products, which involves $\operatorname{costs}\left(\mathrm{c}_{\mathrm{ei}}\right)$.

Delivery of a superior quality product to the final consumer depends on the quality of both the raw and processed material. The company's profitability also depends on the optimization of its production processes, which requires controlling for product variability. This raises questions about the measurement costs of product attributes. We did not model the distribution system, which can also affect the perceived quality of the final product.

The incentive for the production of quality animals means paying a bonus (b) for attributes that meet the specifications defined by the company. The bonus is paid as a percentage over the market price $(p)$, then $b=\alpha$.p, where $\alpha \in[0,1]$ and $p$ is the market price.

\section{Mathematical model 1: subsystem 1 (vertical coordination)}

In this subsystem, farmers establish direct negotiation with the company that coordinates a quality program. In general, the quality is assessed by the company based on a set of measurable product attributes, the bonus being based on a classification table which assigns awards of different percentages depending on the category in which the lot is considered. The average quality depends not only on specific investments made by the production side, but also on the investments made by the company and by the other agents involved with the distribution to final consumption.

\section{a. Production}

The utility level of the beef supplier with a given level of quality attributes $(M)$ is given by:

$U P=p+b_{e p}(p)-c_{e p}$

The optimal quality required by the company is achieved by the cattle farmer at the point where the marginal benefit equals the marginal cost. In other words:

$b_{e p}=c_{e p}$

As the beef farmer is risk averse, the risk premium (w) of producing a high-quality lot should also be modeled, since the investments made in order to achieve it could be captured as a quasi-rent. Thus:

$U P=p+b_{e p}(p)-c_{e p}-\mathrm{w}$

and

$b_{e p}(p)=c_{e p}+\mathrm{w}$

However, quality has several dimensions, based on the bundle of attributes, and each attribute results from specific investments made by the supplier. The multidimensional character of quality gives more complexity to the structure of incentives, as follows: 
$U P=p+\left[b_{e p^{\prime} 1}(p)+b_{e p^{\prime} 2}(p)+b_{e p^{\prime} 3}(p)+\ldots+b_{e p^{\prime} n}(p)\right]-c_{e p}-\mathrm{w}$

and

$b_{e p^{\prime} 1}(p)+b_{e p^{\prime} 2}(p)+b_{e p^{\prime} 3}(p)+\ldots+b_{e p^{\prime} n}(p)=c_{e p}+\mathrm{w}$

where $b_{e p, i}$ for $i \in\{1, \ldots, n\}$ represents the premium paid for the dimension $\mathrm{i}$.

\section{b. Processing company}

The company's utility function is defined as:

$U I=p_{c}+b_{e i}\left(p_{c}\right)-c_{e i}-p-b_{e p}(p)$

where $\mathrm{p}_{\mathrm{c}}$ is the product price and $b_{e p}(p)=\Sigma_{i}^{n} b_{e p}(p)$. In the presence of a given level of variability, the production costs can be broken down into some related costs: (1) the specific investment costs $\left(\mathrm{c}_{\mathrm{e} i}\right) ;(2)$ the acquisition of raw material (p); and (3) the premium for suppliers of homogenous quality $\left(\mathrm{c}_{\mathrm{v}}\right)$ :

$U I=p_{c}+b_{e i}\left(p_{c}\right)-c_{e i}-p-b_{e p}(p)-c_{v}$

Assuming that the processor is risk neutral to the generated quasi-rents created during industrial processing, ${ }^{2}$ utility maximization occurs when the marginal benefit is equal to the cost of production and transaction:

$b_{e i}\left(p_{c}\right)=c_{e i}+b_{e p}(p)+c_{v}$

\section{c. Production and industry equilibrium}

The balance between production and industry in multidimensional incentive contracts is achieved when the marginal benefits of the agent are at least equal to the marginal benefits of the principal, as presented as:

$\left[b_{e p, 1}(p)+b_{e p, 2}(p)+b_{e p, 3}(p)+\ldots+b_{e p, n}(p)\right]=b_{e i}\left(p_{c}\right)$

From the restriction posed above, incentive contracts between production and industry must be designed in a way that allows a balance between the different incentives for each dimension of quality. In addition, returns associated with specific investments, and the risks, must be considered. Suppliers' risk is exemplified by the risk of quasi-rent capture

\footnotetext{
${ }^{2}$ The final consumer utility, when applied to the model, generates the possibility of quasi-rent capture during the industrial process. This variable should therefore be considered when a more robust analysis is built.
}

generated in the production of a quality lot, and for the company it is variability in the processed product. Thus:

$b_{e p}(p)=c_{e p}+w-c_{e i}-c_{v}$

where $b_{e p}(p)=\Sigma_{i}^{n} b_{e p}(p)$.

In general, the benefit that the company receives when selling high-quality beef to consumers should at least cover the benefits the company pays its suppliers. Similarly, the contract must ensure that the risk of product variability represents part of the cost for the supplier.

\section{Mathematical model 2: subsystem 2 (vertical and horizontal coordination)}

In subsystem 2, a credence good is part of the transaction, and its production implies larger investments by both agents in specific assets compared to subsystem 1 . We treat the case as a credence good ${ }^{3}$ (organic beef), where there is a need for a third party to certify the quality attribute. The bonus for quality is established between the parties (production and industry), and it represents a percentage above the market price. But as it is a product that demands more specific investments, the percentage of bonus is greater than that applied for subsystem 1 . In the presence of horizontal coordination, producers bear the costs of governance $(c g)$ of this institutional arrangement. As in subsystem 1, the final quality depends not only on the specific investments made in production, but also on the investments made by the company and the other agents involved in the distribution to final consumption.

\section{a. Production}

In this subsystem, farmer's utility (UP*) is related to the net economic benefits given by the sum of the market price $(p)$ plus the $\%$ bonus achieved by product differentiation $\left(\mathrm{b}^{*}\right)$ minus the costs of specific investments $\left(\mathrm{c}^{*}{ }_{\mathrm{ei}}\right)$. Horizontal coordination implies positive governance costs $(c g)$, which is modeled as:

$U P^{*}=p+b^{*}{ }_{e p}(p)-c^{*}{ }_{e p}-c_{g}$

where $b^{*}{ }_{e p}(p)=\Sigma_{i}^{n} b^{*}{ }_{e p}(p)$ as, $b^{*}{ }_{e p}>b_{e p}$ e $c^{*}{ }_{e p}>c_{e p^{\prime}}$, where $\mathrm{b}^{*}{ }_{\mathrm{ep}, i}$ to $i \in\{1, \ldots, \mathrm{n}\}$, which represents the bonus paid for the attribute $i$.

It is assumed that $b^{*}{ }_{e p}>b_{e p} e c_{e p}^{*}>c_{e p^{\prime}}$ i.e. the premium received by the farmers in a program of organic meat

\footnotetext{
${ }^{3}$ Organic food can be treated as a credence good since many attributes are based on beliefs. There are organic systems strictly defined based on technical aspects.
} 
production, is higher than that obtained in a program of quality meat. On the other hand, the farmers' specialized investments are assumed to be larger, because in addition to the investments made to obtain a younger herd (subsystem 1), farmers have to adapt their production to the private standards for organic production.

Like in subsystem 1, the investment in quality will only be made based on marginal conditions for optimization. Moreover, as the supplier is risk averse, the risk of quasi-rent capture must also be accounted for. Thus:

$U P^{*}=p+b^{*}{ }_{e p}(p)-c^{*}{ }_{e p}-c_{g}-\mathrm{w}$

and:

$b^{*}{ }_{e p}(p)=c^{*}{ }_{e p}+c_{g}+w$

b. Processing company

Similar to that presented in subsystem 1, the company's utility function is given by:

$U I^{*}=p_{c}+b^{*}{ }_{e i}\left(p_{c}\right)-c^{*}{ }_{e i}-c_{v}-p-b^{*}{ }_{e p}(p)-c_{g}$

where, $b^{*}{ }_{e p}(p)=\Sigma_{i}^{n} b^{*}{ }_{e p}(p) e c^{*}{ }_{e i}>c_{e i}$. Its utility maximization occurs when its marginal benefit rewards its marginal costs, i.e. the bonus paid to suppliers and the costs of the transaction. Thus,

$b^{*}{ }_{e i}\left(p_{c}\right)=c^{*}{ }_{e i}+b^{*}{ }_{e p}(p)+c_{v}$

\section{c. Production and industry equilibrium}

Compared to subsystem 1, the inclusion of governance costs differentiates the condition of equilibrium in subsystem 2. Thus, based on Equations (12) and (14), the balance equation in subsystem 2 is presented in Equation (15) and (16):

$b^{*}{ }_{e p}(p)=b^{*}{ }_{e i}\left(p_{c}\right)$

being $b^{*}{ }_{e p}(p)=\Sigma_{i}^{n} b^{*}{ }_{e p}(p)$ or

$b^{*}{ }_{e p}(p)=c^{*}{ }_{e p}+c_{g}+w-c^{*}{ }_{e i}-c_{v}$

As presented, the incentive structure in subsystem 2 should be designed in such a way that the costs of governance are added to the costs of specific investments and to that of risk capture. Comparing the equilibrium of subsystems 1 and 2 and the equilibrium Equations (9) and (16), it follows that the premium paid to the producer in subsystem 2 must be greater or at least equal to the cost of governance involved in the transaction plus the specific investment and the risk of quasi-rent capture costs. Thus:

$b^{*}{ }_{e p}(p)-b_{e p}(p)=c_{g}$

\section{Strategic model}

The strategic model aims to capture the dynamic aspects of agents' interaction and introduces uncertainty related to bonus incentive transmission along the chain. The mathematical model presented so far assumes that the company would be willing to pay for quality. The strategic model introduces alternatives: (1) farmers choose whether to contract with the company; and (2) the company chooses whether to pay bonuses to farmers. The modeling strategy is developed through a game between the agents, considering the farmers $(\mathrm{P})$ and companies (I).

The payoff matrix represents the possible outcomes of the simultaneous interaction of independent agents, depending on the incentive structure chosen by the agents. It is understood that the incentive transmission is efficient if the bonus received by the agents rewards the specific investments made by them. Therefore, it is assumed that both - farmers and company - are investing in specific assets for achieving quality, but at different levels, depending on the type of subsystem analyzed. It is considered that the larger the asset specificity is, the larger the possibility of capture of quasi-rents and the higher the risk of hold-up occurrence (Klein et al., 1978). There are no technological or organizational constraints for quality production. So, the incentive for quality production depends only on the bonus paid by the consumer and the company in order to remunerate the production and transaction costs. It is assumed that retailers fully transfer the bonus paid to consumer prices.

The farmer's (P) strategic option is whether or not to establish a formal contract with the company in order to supply it. In subsystem 1, the quality achievement is related to investments in animal breeding and animal nutrition, with the purpose of achieving attributes associated with precocity. But precocity presents a positive externality related to the reduction in the animal cycle of production, and consequently to its production cost. In other words, even if the animal does not receive a premium price (bonus), producers indirectly receive some benefit from producing young steers. The choice of subsystem 2 involves the production of quality through credence good (organic beef), for which specific investments are significantly higher for both agents: the investment made by the company in branding the differentiated product, the certification process, and the adoption of an organic production system by producers (time span for technical conversion, third party 
certification and so on). Thus, there is a gradation in the specific investments made by farmers and industry, being higher in subsystem 2.

The choice of contracting implies positive governance costs $c_{g c}$. In general, this should be less than the benefit received by subsystem 1, i.e. $c_{g c}<b_{e p^{\prime}}$ since contracting costs are the same for both subsystems, and $b^{*}{ }_{e p}(p)>b_{e p}(p)$. Thus, if $c_{g c}<b_{e p^{\prime}}$ it is also true that $c_{g c}<b^{*}{ }_{e p}(p)$. Otherwise, given the rationality of agents, the act of contracting would not be a benefit at all. Moreover, as the contract is seen as an incentive structure (Williamson, 1996), it is assumed that if the producers do not choose to contract, it is likely they will not receive the expected full bonus, even when the company pays some amount of premium price. In this scenario (no contract/paid bonus) the bonus is called $b_{e p}^{\prime}$ (subsystem 1) and $b^{\prime \prime}{ }_{e p}(p)$ (subsystem 2); for subsystem $1 b_{e p}^{\prime}<b_{e p^{\prime}}$ and for subsystem $2, b^{\prime \prime}{ }_{e p}<b^{*}{ }_{e p}-c_{g c}$.

The company's decision is whether or not to pay a bonus for the quality delivered by farmers. In paying a bonus, the industry rewards the specific investments made by farmers and the risks of quasi-rent capture involved. The bonus percentage, however, varies depending on the subsystem, either for producers or industry. The premium paid to the producer in subsystem 2 must be greater than that paid in subsystem 1, that is $b_{e p}^{*}>b_{e p^{\prime}}$ and $b^{*}{ }_{e p}>b_{e i^{\prime}}$ since subsystem 2 implies more specific investment. For the company in subsystem 2, the option of not paying a bonus for quality implies a cost called $\Delta \mathrm{t}$, since by not paying a bonus for a highly specific product, the industry incurs the risk of the producer not honoring the transaction in $\mathrm{t}_{2}$. Put differently, by not paying a bonus to a highly specific asset it should be accounted as a present value, i.e. $\left(t_{1}\right)$ the cost of hold- up. Thus, the payoff of the company in subsystem 2, with the option of not paying a bonus, should be discounted $\Delta \mathrm{t}$. It is assumed that $\Delta \mathrm{t} \geq b^{*}{ }_{e p^{\prime}}$ since the hold-up prevents the occurrence of future transactions without a contract between the parties. The game outcomes are presented in Figure 1 and 2.

\section{a. Strategic model 1: vertical coordination (subsystem 1)}

In Q1 - no contract and no payment - farmer's payoff is 0 (zero), since he selects for specific investments and he does not foresee receiving any bonus, but he still has the benefit of having young animals (precocity). ${ }^{4}$ For the company, the payoff is the premium received from the consumer plus the gain of the capture bonus not paid to the producer. In Q3 - with contract and not paying - the producer's payoff is negative, since he bears the governance costs of contracting. Based on the payoff matrix analysis, it is clear that the dominant strategy for the company is not paying bonuses, just as no contract is for producers. The Nash equilibrium occurs in cell $1(\mathrm{Q} 1)$ when the producer does not contract and the company does not pay bonuses. Thus, in subsystem 1, the producer chooses not to sell animals through formal contracts and the company does not pay the premium for the young animal even if receiving a benefit from consumers.

\footnotetext{
${ }^{4}$ The incentive is a result of the collective organization at the first stage. One can see it as payment for the engagement in the collective action.
}

\begin{tabular}{|c|c|c|}
\hline & Not paying & Paying \\
\hline & $0, b_{e i}\left(p_{c}\right)+b_{e p}(p)$ & $b_{e p}(p), b_{e i}\left(p_{c}\right)$ \\
\hline Contract & $-c_{g}, b_{e i}\left(p_{c}\right)+b_{e p}(p)$ & $b_{e p}(p)-c_{g}, b_{e i}\left(p_{c}\right)$ \\
\hline
\end{tabular}

Figure 1. Payoff matrix - model 1.

\begin{tabular}{|c|c|c|}
\hline & Not paying & Paying \\
\hline No contract & $-\Delta_{e p}, b^{*}{ }_{e i}\left(p_{c}\right)+b^{*}{ }_{e p}(p)-\Delta t$ & $-\Delta_{e p}+b_{e p}(p), b_{e i}^{*}\left(p_{c}\right)$ \\
\hline Contract & $-\Delta_{e p}-c_{g}, b_{e i}^{*}\left(p_{c}\right)+b^{*}{ }_{e p}(p)-\Delta t$ & $-\Delta_{e p}-c_{g}+b_{e p}^{*}(p), b_{e i}^{*}\left(p_{c}\right)$ \\
\hline
\end{tabular}

Figure 2. Payoff matrix - model 2. 


\section{b. Strategic model 2: horizontal and vertical coordination (subsystem 2)}

The same exercise performed for subsystem 1 is now developed for subsystem 2 , in which the product is a credence good, the specific investments made by the agents are higher, and there is a cost to the company for opting to not pay a bonus to producers. The outcomes of this strategic interaction of agents are shown in Figure 2.

For subsystem 2, the equilibrium occurs in Q4 - under contract and paying a bonus - the contract adoption being the producer's choice and the payment of premium prices the company's option. In this case, the dominant strategy for the company is paying the bonus, and the Nash equilibrium occurs in Q4.

From the models analyzed (model 1 and model 2), two equilibrium conditions for the studied subsystems are identified: subsystem 1 - vertical coordination of a quality subsystem: producer does not contract for the supply of raw materials and the company does not pay bonuses; and subsystem 2 - horizontal and vertical coordination of a quality subsystem (credence good): formal contract of supply and bonus paid by the company.

\section{Result analysis and validation of hypotheses}

The mathematical models clear the problem of failures in incentive transmission along a productive chain. The strategic model stressed the importance of institutions as incentive structures. The empirical hypotheses and the research questions are compared to the observed results in Table 1.

\section{Quality programs in the Brazilian beef chain: a multiple case study}

An empirical application of the models is carried out by analyzing the quality programs of subsystem 1 and subsystem 2, which differ in product - young steer and organic beef, respectively - and the adopted governance structures - only vertical coordination in subsystem 1 , and horizontal and vertical coordination in subsystem 2 . The three exporting beef processors investigated operate throughout Brazil and represent a large market share in Brazilian beef exportation.

Table 1. Result analysis and validation of hypotheses.

\begin{tabular}{|c|c|c|c|}
\hline Research questions & Hypotheses & Mathematical model & Strategic model \\
\hline $\begin{array}{l}\text { RQ1: What are the } \\
\text { regularities associated } \\
\text { with the failures of the } \\
\text { incentive structure to } \\
\text { promote cooperation? }\end{array}$ & $\begin{array}{l}H 1 \text { : The failure in } \\
\text { coordinating quality } \\
\text { beef subsystems is } \\
\text { related to failures in }\end{array}$ & $\begin{array}{l}\text { The difficulty in aligning the premium the } \\
\text { company receives from consumers with the } \\
\text { benefits paid to suppliers, combining the } \\
\text { multiple aspects of quality (many attributes } \\
\text { are considered/consumers do not pay the same } \\
\text { premium for all beef cuts). } \\
\text { The difficulty in considering the cost of } \\
\text { governance (subsystem 2). }\end{array}$ & \\
\hline $\begin{array}{l}\text { RQ2: What are the } \\
\text { risks perceived by the } \\
\text { players? }\end{array}$ & $\begin{array}{l}\text { the transmission of } \\
\text { monetary incentives } \\
\text { along the chain. }\end{array}$ & $\begin{array}{l}\text { The risk of product variability in the supplier } \\
\text { (farmer) cost. } \\
\text { The farmers' risk of not being paid (by meat } \\
\text { packers) for the specific investments they make. } \\
\text { The meat packing companies' risk of not being } \\
\text { paid (by consumers) for the specific investments } \\
\text { they make. }\end{array}$ & $\begin{array}{l}\text { In subsystem } 1 \text { (low specificity) the Nash } \\
\text { equilibrium is at } Q 1 \text { (the producer does } \\
\text { not contract and industry does not pay } \\
\text { bonuses). There is room for opportunistic } \\
\text { behavior (value capture by the beef } \\
\text { industry). }\end{array}$ \\
\hline $\begin{array}{l}R Q 3 \text { : What role can } \\
\text { institutions play in } \\
\text { fixing the problem? }\end{array}$ & $\begin{array}{l}\text { H2: Formal and informal } \\
\text { institutions affect the } \\
\text { existence, persistence } \\
\text { and intensity } \\
\text { of the observed } \\
\text { organizational failures. }\end{array}$ & & $\begin{array}{l}\text { Institutions have a major role as non- } \\
\text { pecuniary incentive structures - in the } \\
\text { subsystem } 2 \text { matrix the Nash equilibrium } \\
\text { is obtained when there are contracts } \\
\text { and horizontal coordination ( } 04 \text { - under } \\
\text { contract and paying a bonus). }\end{array}$ \\
\hline
\end{tabular}


In subsystem 1, two quality programs coordinated by two meat packers (Alpha and Beta) are analyzed. In subsystem 2 a quality program coordinated by one meat packer (Sigma) is analyzed.

\section{Alpha and Beta companies}

The quality beef programs are organized with the purpose of carcass classification and grading, through which a set of product attributes are evaluated. The Brazilian cattle carcass classification grid, established by Ministerial Decree $n^{\circ} 612 / 89$, emphasizes maturity as a criterion of quality. Other criteria are sex, conformation, fat coverage, and animal weight. Animal maturity is measured by the number of permanent incisor teeth. The quality attributes considered in the companies' programs are: (1) animal gender (male, female, and castrated male); (2) animal maturity (number of permanent incisor teeth); (3) carcass fat coverage; and (4) carcass weight. The premium to be paid to producers is defined based on a combination of the attributes cited above. To achieve the maximum bonus, the animals must combine favorable attributes of weight, maturity, and fat coverage for each category of gender. The premium is paid as a percentage over the market price.

For Alpha company, there is also an additional premium of $1 \%$ for carcasses certified as EurepGap (European Retailer Produce Working Group - Good Agricultural Practices) and for those originating from organic systems. The castrated males command a maximum premium of $4 \%$, and females $7 \%$. The carcasses classified outside the established patterns are subject to penalties through discounts on the market price. It is important to emphasize that in this company all the animals are slaughtered according to the specifications of the quality program. There is no need to pre-register within the program, and after the slaughtering process is completed the producers receive a spreadsheet which certifies the animal performance.

Beta company does not offer a premium for female animals. Only males (castrated steers and young castrated steers) are accepted in the quality program. The requirement of homogeneity in animal lots in Beta company differentiates it from Alpha. The premium is paid only for carcasses from lots which have at least $70 \%$ of the animals classified in their categories. The homogeneity level added to other criteria maturity, fat coverage, sex, and weight - allows a premium that can reach up to $6 \%$. As opposed to Alpha company, at Beta the animals are slaughtered according to quality attributes only when the producers apply to the program. Beta's quality program is restricted to certain regions of the country, while at Alpha the quality classification is present in all industrial units.
Note that under these beef quality programs there are no formal contracts drawn up between producers and the processing companies. The standards required by the companies and the premium levels are explained through booklets and brochures available at the firms' websites. Formal contracts occur only in cases of advance purchase for slaughter, which do not necessarily consider quality attributes. Contractual clauses are related to final prices and not to quality demands for the animal carcasses. However, at Alpha company - where animal classification under the quality program is independent of prior registration - the formal contract for advance purchase presents the carcass standards classification as an appendix to the contract.

For carcass classification, the variables sex, weight, and maturity are easy to measure. Evaluation of fat coverage and animal conformity is carried out based on technicians' subjective experience. Although appropriate measurement tools are available, for instance special rulers for checking fat coverage, they are usually only used in case of doubt about the evaluation. According to the companies, the challenge in implementing quality programs is related to the difficulty in establishing premiums that really serve as an incentive for the production of quality animals. According to them, some beef cuts - even those from premium carcasses - do not command differentiated prices from consumers. Indeed, some of the beef cuts do not command any premium from consumers, which represents a difficulty in establishing a general percentage to pay to producers as an incentive for quality. Moreover, as the quality of beef results from a range of interdependent attributes, it is hard to create an incentive structure that encompasses all the factors required for the production of premium beef in accordance with the interests of the processing company.

\section{Sigma company}

In subsystem 2, the production and marketing of organic beef are conducted through a partnership between farmers and a large Brazilian meat packer (Sigma) which has extensive international market share. This company invested in the development of an organic label and it exports and markets this organic brand with large national and international retailers. Organic animals are produced on farms which are certified by independent companies specialized in auditing organic food production processes. The certifying company is accredited by international institutions. Similarly, the process of animal slaughtering and beef processing is subject to certification by the same auditing firm. The farmers are organized into a producers' association which negotiates the terms of the supply contract. In general, the contract establishes the relationship duration between the parties (currently set at three years), 
the bonus to be paid to cattle raisers (5\% to $10 \%$ above the market price based on a national index), and the criteria for carcass classification (weight, age, and fat cover). Usually, the bonuses received for organic animals are higher than those paid to young steers (subsystem 1), and the meatpacking standard of carcass classification in subsystem 2 is less restrictive than those applied to subsystem 1 , specifically regarding fat coverage and animal maturity (number of permanent incisor teeth). So, in subsystem 2 both parties have a long-term relationship and establish formal contracts, as opposed to what was observed in subsystem 1 . The contract is not collective and each producer has to sign its own document, but the producers' association negotiates the general contract clauses for all cattle raisers. With this horizontal coordination, the producer's bargaining power increases.

\section{A comparative analysis of the empirical cases}

Based on the foregoing, it is possible to identify a set of peculiarities and similarities among the institutional arrangements coordinated by the Alpha, Beta and Sigma companies. The results are presented in Tables 2 and 3. Considering the empirical results, the transmission of incentives in the Sigma company seems to be the most efficient, for several reasons: (1) the product in the Sigma subsystem is a differentiated one, which involves higher specificity (organic beef); (2) the willingness of consumers to pay a differentiated price for all different cuts of organic beef (ideology purposes); (3) the presence of governance structures (contracts) that imply an increased coordination; and (4) the presence of horizontal coordination that enhances farmers' bargaining power in terms of contract negotiation.

Although the meat from young steers is generally recognized as a differentiated product, especially when compared to commodity beef, the acquisition of lots under quality programs occurs through spot market transactions. However, depending on the carcass quality and the respective bonus,

Table 3. Cases: transaction pattern.

\begin{tabular}{llll}
\hline & Alpha & Beta & Sigma \\
Specificity & medium & medium & high \\
Frequency & medium & medium & high \\
Uncertainty & high & high & medium \\
Incentive & low & low & high \\
Formal contracts & no & no & yes \\
Brands & no & yes & yes \\
Certification & no & no & yes \\
Horizontal Coordination & no & no & yes \\
\hline
\end{tabular}

Table 2. Characterization of the empirical cases.

\begin{tabular}{|c|c|c|c|}
\hline & Alpha (subsystem 1) & Beta (subsystem 1) & Sigma (subsystem 2) \\
\hline Quality program objective & $\begin{array}{l}\text { slaughter of young animals, } \\
\text { calves, and heifers }\end{array}$ & $\begin{array}{l}\text { slaughter of young animals: } \\
\text { young steers }\end{array}$ & slaughter of organic cattle \\
\hline $\begin{array}{l}\text { Attributes for animal } \\
\text { carcass classification }\end{array}$ & $\begin{array}{l}\text { gender; animal maturity; fat } \\
\text { coverage; weight; } \\
\text { production technology; } \\
\text { (EurepGap/ organic) }\end{array}$ & $\begin{array}{l}\text { gender; animal maturity; } \\
\text { fat coverage; weight; batch } \\
\text { homogeneity; production } \\
\text { technology; (EurepGap/ } \\
\text { organic) }\end{array}$ & $\begin{array}{l}\text { gender; animal maturity; fat } \\
\text { coverage; weight }\end{array}$ \\
\hline Incentive & $\begin{array}{l}\% \text { bonus (above the market } \\
\text { price) }\end{array}$ & $\begin{array}{l}\% \text { bonus (above the market } \\
\text { price) }\end{array}$ & $\begin{array}{l}\% \text { bonus (above the price } \\
\text { referenced on a national index) }\end{array}$ \\
\hline Maximum premium & $\begin{array}{l}4 \% \text { (male) } \\
7 \% \text { (female) }\end{array}$ & $\begin{array}{l}6 \% \text { (male) } \\
\text { females do not receive } \\
\text { premiums }\end{array}$ & $10 \%$ \\
\hline $\begin{array}{l}\text { Producer registration in the } \\
\text { program }\end{array}$ & $\begin{array}{l}\text { no prior producers' registration } \\
\text { needed to participate in the } \\
\text { program }\end{array}$ & $\begin{array}{l}\text { prior producers' registration } \\
\text { needed to participate in the } \\
\text { program }\end{array}$ & $\begin{array}{l}\text { prior producers' registration } \\
\text { needed to participate in the } \\
\text { program }\end{array}$ \\
\hline Program scope & all industrial plants & $\begin{array}{l}\text { only a few industrial plants } \\
\text { located in certain Brazilian } \\
\text { states }\end{array}$ & $\begin{array}{l}\text { only a few industrial plants } \\
\text { located in certain Brazilian } \\
\text { states }\end{array}$ \\
\hline
\end{tabular}


the final price could be higher than the commodity market price.

The importance of formal (contracts) and informal (collective action) institutions as incentive structures becomes clear in the second subsystem model, which is empirically represented by Sigma. Although the product transacted in the Sigma subsystem is highly specific (organic meat), the findings suggest that the efficiency in incentive transmission is related to institutional mechanisms (the gains from horizontal coordination and contracts) and not only to asset specificity. According to the results presented in the strategic model 2, in the absence of institutional mechanisms there is room to capture part of the value generated in the transaction at the expense of the farmers' earnings. In other words, there is room for failures in incentive transmission along the productive chain.

This argument is confirmed when examining the success of Brazilian marketing alliances in which the transacted product is young steers (medium specificity), the coordination is exercised by the retailer, and there are institutional incentives like contracts and horizontal coordination of producers (e.g. Carrefour Quality Lines). Thus, even with products whose specificity is considered medium (young steers), the existence of contracts and horizontal coordination (association of young steer producers) reduces the inefficiency in the transmission of incentives along the coordinated subsystem.

\section{Conclusions}

Quality attributes are demanded by consumers. Beyond technological issues, organizational aspects are crucial in achieving quality, and coordination aspects assume an important role. Quality programs coordinated by the beef industry represent an initiative to achieve more efficient organizational forms. However, when assessing the duration of these programs it becomes clear that the task is not a trivial one. Designing an appropriate structure of incentives is the challenge posed to these programs. This paper is based on the theory of incentives and Transaction Cost Economics, and it shows that quality production is a multidimensional task involving a set of specific investments, and each one represents a possibility of capturing quasi-rents. Each risk involved should also be considered as an important variable in the theoretical model.

Considering quality as a multidimensional concept, and the necessity of specific investments for its production, imperfect institutional arrangements in quality beef programs can be identified. The complexity of designing efficient incentive structures makes the maintenance of these programs difficult. The problem is that some beef cuts, even those derived from carcasses awarded premiums, are not rewarded in a linear form by the consumer market. Some cuts do not receive any differentiated price, and this compromises the establishment of a premium to be paid to producers. Moreover, the quality results from a set of interdependent attributes which confer complexity to create a compensation structure that incentivizes the production in a balanced form in accordance with the processing company's interest. The producers, in turn, question the effectiveness of these programs, since the final quality of the meat also depends on a set of factors related to the industrial processing and the conditions of storage and transport. They also consider the compensation model to be confusing and complex, and recognize that it is all about the exercise of market power. Legal institutions have a preponderant role to play, especially by allowing both parties to propose clear standards for carcass standardization and classification.

All these uncertainties create a perception of risk, hindering the establishment of formal contracts and maintaining a distrustful relationship between producers and industry. Therefore, investments in producing animals with quality attributes are not properly encouraged by the industry, and those producers willing to make such investments are at risk of value capture. Given this, institutions have a role to play in helping to establish an efficient incentive structure, besides guaranteeing health requirements for livestock and industrial processing, as well as satisfactory conditions throughout the cold chain.

The role of institutions in the promotion of cooperation and, the focus of this research, the role of institutions in preventing inefficient incentive transmission along the chain is confirmed when the outcomes in subsystem 2 are analyzed. Because organic products are related to environmental and health aspects and not to intrinsic beef attributes like, for instance, tenderness, consumers pay premiums for all beef cuts, not just those from the rear of the animal, which are considered prime cuts. On the other hand, due to the greater asset specificity involved, and thus the greater risk of quasi-rent capture, the organic system requires more effective coordination, which is reflected in the need to draw up contracts for supplying animals to industry. The role of governance structures as an incentive mechanism for transaction efficiency is clear. Furthermore, to minimize the risks of incentive transmission failure along the chain, it is important to stress the need for a broad discussion about standard classification criteria. It is also relevant to be aware of the need to implement satisfactory quality requirements for livestock health, industrial processing, cold chain, and storage conditions.

This conclusion makes sense when the agents downstream do not display benevolent behavior. In other words, opportunism is part of the model applied in this research. Otherwise, even if consumers are aware of environmental 
and health issues and they do pay a bonus for all types of beef cuts and not only for prime cuts, the industry could exercise its market power and not reward the producers. The industry could argue that the animal was not classified as a quality one. According to informational asymmetry, the industry could state that after slaughtering the animal some attributes, like fat coverage for instance, were found to be unacceptable, and therefore the animal did not merit a bonus for this classification criterion. Thus, the problem of failures in incentive transmission along the chain is maintained, even in the presence of a high premium paid by retailers and consumers. Considering all these aspects, quality becomes a feasible goal only at low transaction and production costs, and to achieve these, institutional issues must be inserted in the analytical model.

\section{References}

Akerlof, G., 1970. The market for 'lemons': quality uncertainty and the market mechanism. Quarterly Journal of Economics 84: 48-500

Eisenhardt, K.M., 1989. Agency theory: an assessment and review. Academy of Management Review 14: 57-74.

Gibbons, R.,1998. Incentives in organizations. The Journal of Economics Perspectives 12: 115-132.

Holmstrom, B. and P. Milgron, 1991. Multitask principal-agent analyses: incentive contracts, asset ownership and job design. Journal of Law, Economics and Organization 7: 24-38.

Jensen, M.C. and W.H. Meckling, 1976. Theory of the firm: managerial behavior, agency cost and ownership structure. Journal of Financial Economics 3: 305-360.

Klein, B., R.G. Crawford and A.A. Alchian, 1978. Vertical Integration, appropriable rents, and the competitive contracting process. The Journal of Law and Economics 21: 297-326.

MacDonald, J.M. and P. Korb, 2006. Agricultural contracting update: contracts in 2003. Economic Research Service (USDA). Available at: http://www.ers.usda.gov/publications/eib9/eib9_ reportsummary.pdf.

Martinez, S.W. and K. Zering, 2004. Pork quality and the role of market organization. Economic Research Service (USDA). Agricultural economic report 835. Available at: http://www.ers. usda.gov/Publications/AER835/.

Menard, C. and P.G. Klein, 2004. Organizational issues in the agrifood sector: toward a comparative approach. American Journal of Agricultural Economics 86: 746-751.

Menard, C., 1996. On clusters, hybrids and other strange forms: the case of the French poultry industry. Journal of Institutions and Theoretical Economics 152: 154-183.

Simon, H.A., 1991. Organizations and markets. Journal of Economics Perspectives 5: 24-44.

Williamson, O.E., 1985. The economic institutions of capitalism: firms, markets, relational contracts. The Free Press, New York, NY, USA, 450 pp.
Williamson, O.E., 1996. The mechanisms of governance. Oxford University Press, New York, NY, USA, 429 pp.

Zylbersztajn, D. and E.M.M.Q. Farina, 2010. Dynamics of network governance: a contribution to the study of complex forms. Revista Eletrônica de Administração. Read 16. Available at: http://papers. ssrn.com/sol3/papers.cfm?abstract_id=1716302.

Zylbersztajn, D. and P. Zuurbier, 2009. A non-naive explanation of trust: avoiding mistaken decisions for agribusiness chain management. In: Zylbersztajn, D. and O. Omta (eds.) Advances in supply chain analysys in agri-food systems. Editora Singular, São Paulo, Brazil, pp. 17-29.

Zylbersztajn, D., 1996. Governance structures and agribusiness coordination: a transaction cost economics based approach. In: Goldberg, R.A. (ed.) Research in domestic and international agribusiness management: Volume 12. JAI Press Ltd., Hampton Hill, Middlesex, United Kingdom, pp. 245-310.

Zylbersztajn, D., 2005. Papel dos contratos na coordenação agroindustrial: um olhar além dos mercados. Revista de Economia e Sociologia Rural 43: 385-420. 